\section{Original Article}

Check for updates

\section{OPEN ACCESS}

Received: Jun 17, 2018

Revised: Nov 16, 2018

Accepted: Nov 21, 2018

Correspondence to

Vincent Balaya

Gynecologic and Breast Oncologic Surgery Department, Georges Pompidou European Hospital, 20 Rue Leblanc,

75908 Paris Cedex 15, France.

E-mail:vbalaya@hotmail.com

Copyright (C) 2019. Asian Society of Gynecologic Oncology, Korean Society of Gynecologic Oncology

This is an Open Access article distributed under the terms of the Creative Commons Attribution Non-Commercial License (https:// creativecommons.org/licenses/by-nc/4.0/) which permits unrestricted non-commercial use, distribution, and reproduction in any medium, provided the original work is properly cited.

ORCID iDs

Vincent Balaya (D)

https://orcid.org/0000-0002-7561-239X Fabrice Lécuru (D)

https://orcid.org/0000-0002-4071-3932

Laurent Magaud (DD

https://orcid.org/0000-0002-2973-410X Charlotte Ngô (D)

https://orcid.org/0000-0002-6225-8803 Cyrille Huchon (D)

https://orcid.org/0000-0001-5334-6345 Anne-Sophie Bats (D)

https://orcid.org/0000-0001-5333-3296

Patrice Mathevet (ID)

https://orcid.org/0000-0003-2782-4504

\title{
Perioperative morbidity of radical trachelectomy with lymphadenectomy in early-stage cervical cancer: a French prospective multicentric cohort
}

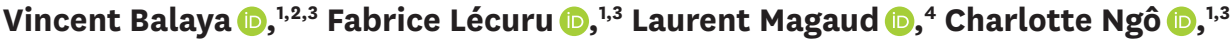 Cyrille Huchon $\mathbb{D},{ }^{5}$ Anne-Sophie Bats $\mathbb{D},{ }^{1,3}$ Patrice Mathevet $\mathbb{B}^{6}$}

\author{
'Gynecologic and Breast Oncologic Surgery Department, Georges Pompidou European Hospital, Paris, \\ France \\ ${ }^{2}$ Research unit in Morphogenesis, Radiology and Anatomy EA4465 Paris Descartes Medical School, Paris, \\ France \\ ${ }^{3}$ Faculty of Medicine, Paris Descartes University, Paris, France \\ ${ }^{4}$ Hospices Civils de Lyon, Pôle IMER, Lyon, France \\ ${ }^{5}$ Obstetrics and Gynecology Department, Poissy Medical Center, Poissy, France \\ ${ }^{6}$ Gynecology Department, University Hospital, University of Lausanne, Lausanne, Switzerland
}

\section{ABSTRACT}

Objective: The aim of this study was to determine the predictive factors of postoperative morbidity of patients who have undergone a radical trachelectomy (RT) for early-stage cervical cancer and to assess the oncologic outcomes.

Methods: We retrospectively analysed the data of 2 prospective trials on sentinel node biopsy for cervical cancer (SENTICOL I and II). Patients having a RT for early-stage cervical cancer with negative sentinel lymph node and safe margins, were included.

Results: Forty-nine patients met the inclusion criteria. Forty-five patients had a laparoscopicassisted vaginal technique and 4 patients a total laparoscopic technique. The median age was 32 years (range, $22-46$ years). $83.7 \%$ of patients had a stage IB1 disease. There were $63.3 \%$ squamous cell carcinomas and $34.7 \%$ adenocarcinomas. The median follow-up was 46 months (range, 1-85 months). Two patients (3.3\%) had a severe postoperative complication (Clavien-Dindo $\geq \mathrm{III}$ and/or CTCAE $\geq 3$ ). The main postoperative complications were urinary $(28.6 \%)$, lymphovascular $(26.5 \%)$ and neurologic $(14.3 \%)$. On a multivariate analysis, postoperative complications were significantly associated with history of pelvic surgery and IB1 International Federation of Gynecology and Obstetrics stage. Inclusion in high surgical skills centers decrease the risk of postoperative complications. During the follow-up, 3 patients $(6.1 \%)$ had a local recurrence and one patient died from a breast cancer. Between group with complications and group without any complications, overall survival and recurrence-free survival did not significantly differ at 5-year of follow-up.

Conclusion: RT has few severe postoperative complications and appears as a safe alternative to spare fertility of young patients. To guarantee best surgical outcomes, patients should be referred to expert center.

Keywords: Cervical Cancer; Trachelectomy; Morbidity 


\section{Presentation}

This study was partially presented at the annual meeting of the Society of Gynecologic Oncology in March 2017 in National Harbour (US) and at the annual meeting of the American Society of Clinical Oncology in June 2017 in Chicago (US).

Conflict of Interest

No potential conflict of interest relevant to this article was reported.

Author Contributions

Conceptualization: B.V., M.P., L.F.; Formal

analysis: M.P., L.F., B.A.S., M.L.; Funding

acquisition: B.V., M.P., L.F., M.L., B.A.S.;

Investigation: M.P., L.F., B.A.S., M.L.;

Methodology: B.V., M.P., L.F., M.L.; Resources:

M.P., L.F., M.L.; Supervision: M.P., L.F.;

Validation: B.V., M.P., N.C., H.C., L.F.; Writing -

original draft: B.V., M.P., L.F., N.C., H.C.; Writing

- review \& editing: B.V., M.P., L.F.

\section{INTRODUCTION}

The radical vaginal trachelectomy was first described by Dargent in 1994 and the first series of 56 patients was published in 2000 [1]. Radical trachelectomy (RT) is a conservative treatment for early-stage cervical cancer consisting in removing the uterine cervix, the parametrium and sparing the remaining uterus. Indications are not so rare since about $42 \%$ of early stages are diagnosed before 40 years old [2]. Moreover, $48 \%$ of women younger than 40 years, who underwent radical hysterectomy, were in fact eligible for trachelectomy [3]. Criteria for performing RT were proposed in 1998 and in the last European Society of Gynaecological Oncology (ESGO) guidelines: desire to preserve fertility; of reproductive age; usual histologic type including squamous carcinoma or adenocarcinoma histology; International Federation of Gynecology and Obstetrics (FIGO) stage IA1 with lymphovascular space invasion, IA2, or IB1; tumor size less than $20 \mathrm{~mm}$ with limited endocervical extension; and no evidence of lymph node metastasis $[4,5]$.

To date, more than 2,700 cases have been published and more than 900 deliveries have been reported [6]. The feasibility of RT with vaginal, abdominal, laparoscopic and robotic technique have been proven with similar oncologic outcomes [7-11]. However, few prospective data are available on the postoperative morbidity after RT and their consequences on oncologic outcomes.

The main objective of this study was to assess the postoperative morbidity after RT for early-stage cervical cancer. The secondary objectives were to determine risk factors of postoperative complications and their impact on oncologic outcomes.

\section{MATERIALS AND METHODS}

\section{Population study}

We realised an ancillary study on the database of 2 prospective French multicentric studies on sentinel lymph node (SLN) biopsy (SENTICOL I and II). Patients with early cervical cancer (stage IA1 with lymphovascular emboli to stage IIA1), no suspicious nodes at preoperative imaging and squamous cell, adenocarcinoma or adenosquamous histology were prospectively included.

SENTICOL I was a prospective multicenter study assessing the diagnostic value of SLN biopsy in early-stage cervical cancer. One hundred and forty-five patients were enrolled between January 2005 and May 2007 and 139 patients were included in a modified intentionto-diagnose analysis [12]. SENTICOL II was a prospective randomized multicenter study assessing morbidity and quality of life [13]. Two hundred and sixty-seven patients were enrolled and 206 patients with negative SLN at frozen-section examination were randomised between SLN biopsy only (105 patients) or SLN biopsy with full pelvic lymph node dissection (101 patients). In both studies, postoperative complications were prospectively recorded. A radical hysterectomy or a RT were performed in case of negative SLN at frozen-examination. Twenty-three centers participated to the 2 studies.

We performed a retrospective analysis of the two databases. We included cases that underwent a RT. Young patients who aimed to spare their fertility with tumor size smaller than $20 \mathrm{~mm}$ were eligible for RT in case of negative SLN at frozen section (FS). Patients who 
had only node staging, had non-radical surgery (simple trachelectomy), patients with positive SLN, extracervical lesion or positive margins were excluded.

The laparoscopic-assisted vaginal RT technique has already been described thoroughly elsewhere $[1,14]$ and only few patients had a non-vaginal surgical approach. Shortly, the procedure started with a laparoscopic pelvic lymph node dissection. In Senticol 1, patients had a SLN biopsy and had systematically an additional pelvic lymphadenectomy whereas in Senticol 2, patients had a SLN biopsy and an additional pelvic lymphadenectomy according to the randomisation. The nodal dissection was performed through transperitoneal approach. Removed lymph nodes (or only the SLNs) had a FS. In case of negative FS, RT was realised through a vaginal approach. The main steps of the procedure were: dissection of a 2-cm vaginal cuff, dissection of the bladder and the ureters, opening the Douglas pouch and bilateral proximal parametrectomy after identification of the uterine artery. The cervix was cut $5 \mathrm{~mm}$ below the isthmus. The specimen was sent for immediate pathological examination, for checking free endocervical margin. Then the pouch of Douglas was closed, and a permanent cerclage was put at the level of the isthmus. Finally, the vagino-isthmic anastomosis was performed.

\section{Data analysis}

Data were extracted from the two prospective data bases. For each patient, we reviewed demographic characteristics (age at diagnosis, body mass index [BMI], and parity), surgical history, and clinical data (preoperative loop electrical excision procedure [LEEP], FIGO stage). We noted the results of preoperative biopsy and the tumor size at preoperative imaging. Operative records were reviewed, and data were collected about the type of surgical approach, the type of surgery performed, the type of lymph node staging (SLN biopsy only or additional pelvic lymphadenectomy), and the number of lymph node removed. Pathological data was reviewed and included tumor histology, lymphovascular space invasion, nodal status, number or removed nodes, parametrial status, vaginal margin status, surgical margin status, and tumor size.

Intraoperative and postoperative complications were recorded according to time of onset (early complications $\leq 30$ days after surgery and late complications $>30$ days after surgery). Levels of complications were assessed according to Clavien-Dindo classification for earlycomplications and according to the CTCAE classification $\mathbf{4} 4.03$ for late complications [15]. A severe complication was defined as grade $\geq 3$ in the Clavien-Dindo classification, necessitating a radiologic or surgical operation, or as grade $\geq 3$ in the CTCAE classification. Given the initial design of SENTICOL I and II, pregnancy rates were not specifically assessed. To assess the surgical skills of each center, we defined 2 types of inclusion center according to the number of patients included type 1 ( $<10$ patients), and type 2 ( $>10$ patients).

\section{Statistical analysis}

Morbidity data were described as number (\%) for qualitative variables and mean (range) for quantitative data. We divided the patients into 2 groups based on presence or absence of complications. In order to determine risk factors of postoperative complications, a univariate analyse was performed. Qualitative variables were compared by applying the $\chi^{2}$ test (or Fisher's test if the sample size was too small) and quantitative variables the Student's t-test. Values of p lower than 0.05 were considered as significant.

Variables associated with $\mathrm{p}$ value lower than 0.2 by univariate analysis were entered into a multivariate logistic regression model in order to identify variables independently associated with postoperative complications of RT. 
Overall survival and free-recurrence survival were analysed by using Kaplan-Meier analysis and compared by applying log-rank test.

Data were recorded in an Excel files and statistical analyses were done using XLStat v19.4 (AddInsoft, Paris, France) and Stata v13.0 (Stata Corp., College Station, TX, USA).

\section{RESULTS}

Between January 2005 and July 2012, 412 patients have been enrolled in SENTICOL I and SENTICOL 2 studies in 23 French centers. Forty-nine patients from 8 centers were finally included in the present study (Fig. 1).

\section{Patient characteristics}

The median age was 32 years (22-46) and the median body mass index (BMI) was $20.8 \mathrm{~kg} /$ $\mathrm{m}^{2}$ (15.8-38.2). Patients were nulliparous in $51 \%$ of cases (25/49). Most of the patients had FIGO stage IB1 disease (83.7\%). Thirty-three patients $(68.8 \%)$ had a previous conisation. The majority of patients had squamous cell carcinoma (63.3\%), 17 patients had adenocarcinoma $(34.7 \%)$ and one patient had adenosquamous carcinoma (2\%). Among the 39 patients who had a preoperative imaging, 4 patients $(10.3 \%)$ had a tumor size larger than $20 \mathrm{~mm}$. The sociodemographic and clinical characteristics are shown in Table 1. No patients received neoadjuvant brachytherapy.

The laparoscopic-assisted radical vaginal trachelectomy (LARVT) was the main surgical approach (45 patients, $91.8 \%$ ) whereas only 4 patients $(8.2 \%)$ had total laparoscopic approach. No laparoconversion was performed. The mean-length operating time was $264 \pm 61$ minutes (165-435).



Fig. 1. Flow-chart of the population study. SLN, sentinel lymph node. 
Table 1. Clinicopathologic and surgical characteristics of patients

\begin{tabular}{|c|c|}
\hline Total population $(n=49)$ & Values \\
\hline \multicolumn{2}{|l|}{ Type of inclusion center } \\
\hline Type 1 & $25(51.0)$ \\
\hline Type 2 & $24(49.0)$ \\
\hline \multicolumn{2}{|l|}{ Age (yr) } \\
\hline Median & $32(22-46)$ \\
\hline$<30$ & $14(28.6)$ \\
\hline$\geq 30$ & $35(71.4)$ \\
\hline \multicolumn{2}{|l|}{ BMI $\left(\mathrm{kg} / \mathrm{m}^{2}\right)$} \\
\hline Median & $20.8(15.8-38.2)$ \\
\hline$<18.5$ & $7(14.3)$ \\
\hline$\geq 18.5$ and $<25$ & $31(63.3)$ \\
\hline$\geq 25$ and $<30$ & $6(12.2)$ \\
\hline$\geq 30$ & $5(10.2)$ \\
\hline \multicolumn{2}{|l|}{ Parity } \\
\hline 0 & $25(51.0)$ \\
\hline$\geq 1$ & $24(49.0)$ \\
\hline \multicolumn{2}{|l|}{ History of previous pelvic surgery } \\
\hline 0 & $33(67.3)$ \\
\hline$\geq 1$ & $16(32.7)$ \\
\hline \multicolumn{2}{|l|}{ FIGO stage } \\
\hline IA1 with emboli & $2(4.1)$ \\
\hline IA2 & $6(12.2)$ \\
\hline IB1 & $41(83.7)$ \\
\hline \multicolumn{2}{|l|}{ Histology } \\
\hline Squamous cell carcinoma & $31(63.3)$ \\
\hline Adenocarcinoma & $17(34.7)$ \\
\hline Adenosquamous & $1(2.0)$ \\
\hline \multicolumn{2}{|l|}{ Presence of LVSI in the biopsy } \\
\hline Yes & $8(16.3)$ \\
\hline No & $38(77.6)$ \\
\hline Not specified & $3(6.1)$ \\
\hline \multicolumn{2}{|l|}{ Tumor size at preoperative imagery $(\mathrm{mm})$} \\
\hline$\leq 20$ & $35(71.4)$ \\
\hline$>20$ & $4(8.2)$ \\
\hline Not specified & $10(20.4)$ \\
\hline \multicolumn{2}{|l|}{ Preoperative LEEP } \\
\hline Yes & $33(68.8)$ \\
\hline No & $16(31.3)$ \\
\hline \multicolumn{2}{|l|}{ Type of surgical approach } \\
\hline LARVT & $45(91.8)$ \\
\hline Laparoscopy & $4(8.2)$ \\
\hline Mean length of operative time (min) & $264 \pm 61(165-435)$ \\
\hline \multicolumn{2}{|l|}{ Type of lymph node staging } \\
\hline SLN alone & $14(28.6)$ \\
\hline $\mathrm{SLN}+\mathrm{PL}$ & 35 (71.4) \\
\hline \multicolumn{2}{|l|}{ SLN detection } \\
\hline No SLN & 0 \\
\hline Unilateral & $2(4.1)$ \\
\hline Bilateral & 47 (95.9) \\
\hline Type of SLN & 179 \\
\hline Blue and Hot & $124(69.3)$ \\
\hline Hot & $32(17.9)$ \\
\hline Blue & $23(12.8)$ \\
\hline Topography of SLN & 179 \\
\hline Ilio-obturator/External iliac area & 148 (82.7) \\
\hline Common iliac area & 21 (11.7) \\
\hline Parametrial area & $7(3.9)$ \\
\hline Promontory area & 0 \\
\hline Paraaortic area & $3(1.7)$ \\
\hline
\end{tabular}




\begin{tabular}{lc} 
Table 1. (Continued) Clinicopathologic and surgical characteristics of patients & \\
\hline Total population $(n=49)$ & Values \\
\hline Number of removed nodes & $3(1-8)$ \\
$\quad$ Number of SLN per patient & $13(4-32)$ \\
$\quad$ Number of non-SLN per patient if PL done & \\
Final pathologic exam & $45(91.8)$ \\
$\quad$ Tumor size (mm) & $4(8.2)$ \\
$\quad \leq 20$ & $9(18.4)$ \\
$>20$ & $40(81.6)$ \\
LVSI & \\
Yes & 0 \\
No & $49(100.0)$ \\
SLN status &
\end{tabular}

Values are presented as number of patients (\%) or median (range).

BMI, body mass index; LARVT, laparoscopic-assisted radical vaginal trachelectomy; LEEP, loop electrical excision procedure; LVSI, lymphovascular space invasion; PL, pelvic lymphadenectomy; SLN, sentinel lymph node.

Fourteen patients (28.6\%) had a SLN biopsy alone and $35(71.4 \%)$ had an additional pelvic lymphadenectomy. No SLN was found on one side in 2 patients (4.1\%) who underwent subsequently an ipsilateral complete pelvic lymphadenectomy in the same operation. The median number of removed SLN per patient was 3 (1-8). In case of additional pelvic lymphadenectomy, the mean number of removed non-SLN per patient was 13 (4-32). Most of SLN $(82.7 \%)$ were found in ilio-obturator or external iliac area (Table 2).

At final pathologic examination, the median maximal size of the tumor was $14 \mathrm{~mm}$ (2-30) and $8.2 \%$ of patients had a tumor size larger than $20 \mathrm{~mm}$. No patients received adjuvant chemotherapy or radiotherapy.

\section{Perioperative outcomes}

Overall, 42 complications were reported in 27 patients $(55.1 \%)$ whereas 22 patients $(44.9 \%)$ were free of complications.

One patient had an intraoperative complication due to an iliac artery injury during the pelvic lymphadenectomy but no laparoconversion were necessary neither transfusion. No bowel or bladder injury was reported.

Two patients (3.3\%) had severe postoperative complications (defined as Clavien-Dindo $\geq \mathrm{III}$ and/ or CTCAE $\geq 3$ ). One patient had a peritonitis secondary to a lymphocyst infection which was radiologically drained 2 weeks after surgery. One patient had a hydronephrosis due to a unilateral ureteral stenosis at 7 weeks after surgery. No pulmonary embolism or death were reported.

The urinary complications were the most frequent complications with 19 complications occurred in 14 patients $(28.6 \%)$. Most of them were minor urinary infection $(8 / 14)$ which occurred during the first 2 weeks after surgery. Dysuria was observed in 4 patients $(8.2 \%)$. Thirteen patients (26.5\%) had 17 lymphovascular complications. Lower limbs lymphedema was unilateral in 3 cases and bilateral in 5 cases. Seven patients (14.3\%) had 7 non-severe neurologic complications. Among them, one patient kept paresthesia of the genito-femoral nerve 16 weeks after surgery and one patient had a unilateral little weakness of the obturator nerve 13 weeks after surgery. Overall complications are summarised in Table 2. 


\begin{tabular}{|c|c|}
\hline Variable $(n=49)$ & Values \\
\hline \multicolumn{2}{|l|}{ Number of complications per patient } \\
\hline None & $22(44.9)$ \\
\hline 1 & $16(32.7)$ \\
\hline 2 & $7(14.3)$ \\
\hline 3 & $4(8.2)$ \\
\hline \multicolumn{2}{|c|}{ Clavien-Dindo classification (maximal grade/patient) } \\
\hline None & $22(44.9)$ \\
\hline I & $9(18.4)$ \\
\hline II & $9(18.4)$ \\
\hline IIIa & 0 \\
\hline $\mathrm{IIIb}$ & $1(2.0)$ \\
\hline IVa & 0 \\
\hline \multicolumn{2}{|c|}{ CTCAE classification (maximal grade/patient) } \\
\hline None & $22(44.9)$ \\
\hline 1 & $7(14.3)$ \\
\hline 2 & $10(20.4)$ \\
\hline 3 & $1(2.0)$ \\
\hline 4 & 0 \\
\hline \multicolumn{2}{|l|}{ Urinary tract complications } \\
\hline Lower tract urinary infections & $8(16.3)$ \\
\hline Upper tract urinary infections & $1(2.0)$ \\
\hline Dysuria & $4(8.2)$ \\
\hline Stress urinary incontinence & $4(8.2)$ \\
\hline Hydronephrosis & $1(2.0)$ \\
\hline \multicolumn{2}{|l|}{ Lymphovascular complications } \\
\hline Lower limb lymphedema & $9(18.4)$ \\
\hline Lymphocyst & $5(10.2)$ \\
\hline Other & $2(4.1)$ \\
\hline \multicolumn{2}{|l|}{ Neurologic complications } \\
\hline Obturator nerve & $4(8.2)$ \\
\hline Genito-femoral nerve & $3(6.1)$ \\
\hline \multicolumn{2}{|l|}{ Thrombo-embolic complications } \\
\hline Limb venous thrombosis & 0 \\
\hline Pulmonary embolism & 0 \\
\hline
\end{tabular}

Values are presented as number of patients (\%).

\section{Predictive factors of postoperative complications}

In univariate analysis, postoperative complications were more common in patients with IB1 FIGO stage (26/41 patients) than in patients with IA1-IA2 FIGO stage (1/7 patients), 63.4\% vs. $12.5 \%$, respectively $(\mathrm{p}=0.008)$. Patients with previous pelvic surgery had more postoperative complications than patients who never had pelvic surgery, $75 \%$ vs. $45.5 \%$, respectively $(\mathrm{p}=0.05)$. Patients who have been operated in type 2 inclusion center seemed to have less postoperative complications (10/24 patients, $41.7 \%$ ) than patients from type 1 inclusion center $(17 / 25$ patients, $68 \%)$.

The risk of postoperative complications was not associated with the age at diagnosis, the tumor histology, the number of SLN or non-SLN removed and the topography of SLNs (Table 3).

Multivariate logistic regression determined 2 factors independently associated with the risk of postoperative complications: history of previous pelvic surgery (adjusted odds ratio $[\mathrm{aOR}]=13.17$; 95\% confidence interval $[\mathrm{CI}]=1.38-125.98 ; \mathrm{p}=0.03$ ) and IB1 FIGO stage $(\mathrm{aOR}=11.72 ; 95 \% \mathrm{CI}=1.22-112.32 ; \mathrm{p}=0.03)$. Patients who have been operated in in type 2 inclusion center had lower risk of postoperative complications (aOR=0.19; 95\% CI $=0.04-$ 0.97; $\mathrm{p}=0.046$ ) (Table 4). 
Table 3. Univariate analysis of risk factors of postoperative morbidity

\begin{tabular}{|c|c|c|c|}
\hline Predictive variable & Group without complications $(n=22)$ & Group with complications $(\mathrm{n}=27)$ & $p$ \\
\hline Type of inclusion center & & & 0.06 \\
\hline Type 1 & $8(36.4)$ & $17(63)$ & \\
\hline Type 2 & $14(63.6)$ & $10(37)$ & \\
\hline \multicolumn{4}{|l|}{ Age (yr) } \\
\hline Mean & $32.9 \pm 5.2(25-46)$ & $32.6 \pm 5.4(22-42)$ & 0.82 \\
\hline$<30$ & $6(27.3)$ & $8(29.6)$ & 0.86 \\
\hline$\geq 30$ & $16(72.7)$ & $19(70.4)$ & \\
\hline \multicolumn{4}{|l|}{$\operatorname{BMI}\left(\mathrm{kg} / \mathrm{m}^{2}\right)$} \\
\hline Mean & $22.8 \pm 5.6(15.8-38.2)$ & $22.1 \pm 3.8(17-32.8)$ & 0.63 \\
\hline$<18.5$ & $5(22.7)$ & $2(7.4)$ & 0.13 \\
\hline$\geq 18.5$ and $<25$ & $10(45.5)$ & $21(77.8)$ & \\
\hline$\geq 25$ and $<30$ & $4(18.2)$ & $2(7.4)$ & \\
\hline$\geq 30$ & $3(13.6)$ & $2(7.4)$ & \\
\hline Parity & & & 0.48 \\
\hline 0 & $10(45.5)$ & $15(55.6)$ & \\
\hline$\geq 1$ & $12(54.5)$ & $12(44.4)$ & \\
\hline History of previous pelvic surgery & & & 0.05 \\
\hline 0 & $18(81.8)$ & $15(55.6)$ & \\
\hline$\geq 1$ & $4(18.2)$ & $12(44.4)$ & \\
\hline FIGO stage & & & 0.008 \\
\hline IA1 with emboli - IA2 & $7(31.8)$ & $1(3.7)$ & \\
\hline IB1 & $15(68.2)$ & $26(96.3)$ & \\
\hline Histology & & & 0.59 \\
\hline Squamous cell carcinoma & $15(68.2)$ & $16(59.3)$ & \\
\hline Adenocarcinoma & $7(31.8)$ & $10(37.0)$ & \\
\hline Adenosquamous & 0 & $1(3.7)$ & \\
\hline Presence of LVSI in the biopsy & & & 0.88 \\
\hline Yes & 4 (18.2) & $4(14.8)$ & \\
\hline No & $17(77.3)$ & $21(77.8)$ & \\
\hline Not specified & $1(4.5)$ & $2(7.4)$ & \\
\hline Tumor size at preoperative imagery (mm) & & & 0.93 \\
\hline$\leq 20 \mathrm{~mm}$ & $16(72.7)$ & $19(70.4)$ & \\
\hline$>20 \mathrm{~mm}$ & $2(9.1)$ & $2(7.4)$ & \\
\hline Not specified & $4(18.2)$ & $6(22.2)$ & \\
\hline Preoperative LEEP & & & 0.27 \\
\hline Yes & $13(59.1)$ & $20(74.1)$ & \\
\hline No & $9(40.9)$ & $7(25.9)$ & \\
\hline Type of surgical approach & & & 0.06 \\
\hline LARVT & $22(100.0)$ & $23(85.2)$ & \\
\hline Laparoscopy & 0 & $4(14.8)$ & \\
\hline Mean length of operative time (min) & $270.4 \pm 92.7(211-435)$ & $262.6 \pm 52.7(165-360)$ & 0.81 \\
\hline Type of lymph node staging & & & 0.41 \\
\hline SLN alone & $5(22.7)$ & $9(33.3)$ & \\
\hline$S L N+P L$ & $17(77.3)$ & $18(66.7)$ & \\
\hline SLN detection & & & 0.88 \\
\hline Unilateral & $1(4.5)$ & $1(3.7)$ & \\
\hline Bilateral & $21(95.5)$ & $26(96.3)$ & \\
\hline Type of SLN & & & 0.5 \\
\hline Blue and hot & $57(68.7)$ & $67(69.8)$ & \\
\hline Hot & $13(15.7)$ & $19(19.8)$ & \\
\hline Blue & $13(15.7)$ & $10(10.4)$ & \\
\hline Total & $83(100.0)$ & $96(100.0)$ & \\
\hline Topography of SLN per patient & & & 0.35 \\
\hline Patients with SLN only in Ilio-obturator/external iliac area & $18(81.8)$ & $19(70.4)$ & \\
\hline Patients with at least one SLN in atypical area & $4(18.2)$ & $8(29.6)$ & \\
\hline
\end{tabular}

(continued to the next page) 
Table 3. (Continued) Univariate analysis of risk factors of postoperative morbidity

\begin{tabular}{|c|c|c|c|}
\hline Predictive variable & Group without complications $(n=22)$ & Group with complications $(n=27)$ & $p$ \\
\hline Number of removed nodes & & & 0.76 \\
\hline Number of SLN per patient & $3.8 \pm 1.7(1-8)$ & $3.9 \pm 2(2-8)$ & \\
\hline Number of non-SLN per patient if PL done & $15.3 \pm 6.5(4-27)$ & $14.6 \pm 6.7(8-32)$ & \\
\hline \multicolumn{4}{|l|}{ Final pathologic exam } \\
\hline Tumor size (mm) & & & 0.21 \\
\hline$\leq 20$ & $19(86.4)$ & $26(96.3)$ & \\
\hline$>20$ & $3(13.6)$ & $1(3.7)$ & \\
\hline LVSI & & & 0.48 \\
\hline Yes & $5(22.7)$ & $4(14.8)$ & \\
\hline No & $17(77.3)$ & $23(85.2)$ & \\
\hline
\end{tabular}

Values are presented as number of patients (\%) or median (range).

BMI, body mass index; FIGO, International Federation of Gynecology and Obstetrics; LARVT, laparoscopic-assisted radical vaginal trachelectomy; LEEP, loop electrical excision procedure; LVSI, lymphovascular space invasion; PL, pelvic lymphadenectomy; SLN, sentinel lymph node.

Table 4. Multivariate analysis of risk factors of postoperative morbidity

\begin{tabular}{|c|c|c|c|}
\hline Variable & $\mathrm{aOR}$ & $95 \% \mathrm{Cl}$ & $p$ \\
\hline \multicolumn{4}{|l|}{ Type of inclusion center } \\
\hline Type 1 & 1 & & \\
\hline Type 2 & 0.19 & $0.04-0.97$ & 0.046 \\
\hline \multicolumn{4}{|l|}{ BMI $\left(\mathrm{kg} / \mathrm{m}^{2}\right)$} \\
\hline$\geq 18.5$ and $<25$ & 1 & & \\
\hline$<18.5$ & 0.39 & $0.05-2.85$ & 0.35 \\
\hline$\geq 25$ and $<30$ & 0.06 & $0.01-1.07$ & 0.06 \\
\hline$\geq 30$ & 0.1 & $0.01-2.5$ & 0.16 \\
\hline \multicolumn{4}{|c|}{ History of previous pelvic surgery } \\
\hline 0 & 1 & & \\
\hline$\geq 1$ & 13.17 & $1.38-125.98$ & 0.03 \\
\hline \multicolumn{4}{|l|}{ FIGO stage } \\
\hline IA1 with emboli - IA2 & 1 & & \\
\hline IB1 & 11.72 & $1.22-112.32$ & 0.03 \\
\hline \multicolumn{4}{|l|}{ Type of surgical approach } \\
\hline Laparoscopy & 1 & & \\
\hline LARVT & 0.01 & $0.00-2.83$ & 0.11 \\
\hline
\end{tabular}

aOR, adjusted odds ratio; BMI, body mass index; $\mathrm{Cl}$, confidence interval; FIGO, International Federation of Gynecology and Obstetrics; LARVT, laparoscopic-assisted radical vaginal trachelectomy.

\section{Follow-up and oncologic outcomes}

The median follow-up was 46 months (1-85). Only one patient had a secondary simple hysterectomy for non-oncologic reasons 5 months later. During follow-up, one patient was lost to follow-up (2\%) and 3 patients had recurrent disease (6.1\%). The first patient had a local recurrence at 13 months after surgery on the upper part of the vagina and necessitated a secondary surgery with radical hysterectomy and concomitant chemoradiotherapy. The second patient had a local recurrence on the upper part of the vagina 31 months after surgery and the third patient had one metastatic inguinal node 55 months after surgery. These 2 patients received radiotherapy and chemotherapy without secondary surgery. For these 3 patients, the tumor size were respectively 13,15 , and $18 \mathrm{~mm}$. One patient died of breast cancer 41 months after surgery, without any sign of recurrence of cervical disease.

Overall survival and recurrence-free survival rates did not significantly differ at 5 -year of follow-up between patients with and without complication $(100 \%$ vs. $95.5 \%, p=0.33$ and $96.3 \%$ vs. $90.9 \%$, $\mathrm{p}=0.27$, respectively). 


\section{DISCUSSION}

$\mathrm{RT}$ is now widely proposed to young patients with early cervical cancer. Prospective data concerning postoperative morbidity and its potential impact on survival are lacking. We decided to perform a retrospective analysis on two databases coming from prospective trials on early cervical cancer.

This study shows that the overall rate of complications is important ( $55.1 \%$ of patients) but intraoperative and severe postoperative complications are rare, $2 \%$ and $4.1 \%$ respectively. The most frequent complication is urinary infection. Dysuria was recorded in $8.2 \%$ of women. These rates are comparable to those of radical hysterectomy $[14,16,17]$ and RT appears as safe as radical hysterectomy for young patients who wish to preserve their fertility.

Only one intraoperative complication occurred and consisted in vessels injury during the nodal dissection. They are not linked to the trachelectomy itself but should be considered since the nodal dissection and preparation of obturator fossa are the first steps of the procedure. This rate is in accord with major papers. With Dargent's procedure, intraoperative complication rate was estimated at $3.7 \%$ in 1,364 patients [1,9,14,16,18-21]. Complications occurred during pelvic lymphadenectomy step with vessels injury and during vaginal step with bladder and ureteric injuries [11]. In a cohort of 107 abdominal RT, Li et al. [22] reported a lower intraoperative complication rate of $1.9 \%$. However, intraoperative complications seem to be more severe by laparotomy [11].

In our series, 20.4\% patients had at least a complication assessed grade $\geq \mathrm{II}$ according to Clavien-Dindo classification and $22.4 \%$ patients had at least a complication assessed grade $\geq 2$ according to the CTCAE classification. These postoperative morbidity rates were comparable to those found in literature $[14,19,21,23,24]$.

One patient had a peritonitis secondary to a lymphocyst infection. This complication was also described by Sonoda et al. [3] in 2 cases, secondaries to a group B streptococcus and they hypothesised that there were a transvaginal contamination during the paravesical dissection.

We noted that 7 patients $(14.3 \%)$ had 7 non-severe neurologic complications and this rate was similar to that found by Alexander-Sefre et al. (14\%) [25] and inferior to that found by Lanowska et al. (21.7\%) [21]. Irritation of the genitofemoral or obturator nerves may be induced by manipulation and direct thermal or electrical injury by monopolar diathermy. Using harmonic scalpel and bipolar diathermy may reduce such complications [25].

In this cohort, laparoscopic-assisted radical vaginal trachelectomy seemed to be a safer approach than total laparoscopic technique but only 4 patients had this last technique. Moreover, no patient had laparotomy, neither robotic-assisted technique. In case of multiple prior conisation that may induce a modification of the anatomy, Sonoda et al. [3] suggested that an abdominal approach should be better than a vaginal approach. However, we did not find a significant increased risk of complication if patients had a previous conisation. The multivariate analysis reported 2 risk factors of complications: previous pelvic surgery and stage IB1. These parameters are difficult to integrate in the decision-making process. As suggested by our results, RT performed in expert centers with high surgical skills may be associated with better surgical outcomes. These results are in concordance with the last ESGO guidelines which recommended that surgery for cervical cancer should be 
performed by gynecologic oncologist and trained surgeon in a specialized team dedicated to management of gynecologic cancers [5].

During follow-up, 3 patients had recurrent disease (6.1\%): two local recurrences and one locoregional recurrence. This recurrent rate was similar to that found in Vaginal RT series $(4.8 \%-5.1 \%)$ [9,20], in LARVT series (5.2\%) [14] and robotic series (5.2\%) [10]. One recurrence occurred more than 4 years after $\mathrm{RT}$ and this highlights the need for long-term follow-up as already suggested by Plante et al. [20] and Hauerberg et al. [9]. Complications had no significant impact on survival.

Given the design of SENTICOL I and II, obstetrical data and outcomes were not specifically recorded and assessed, constituting the main weakness of this study. Another limitation of this study lies in the fact that some details of surgical procedure lacks, such as uterine artery preservation or placement of cerclage, due to this retrospective analyse. The strengths of this study are that all data related to postoperative morbidity were prospectively recorded in a quality-checked database and population study was homogenous with a long followup. Moreover, patients came from multiple institutions taking in account different levels of surgical expertise and different levels of learning curve.

In conclusion, this study using prospective data, confirms that RT has few severe postoperative complications and few recurrences when classical indications are respected. RT appears as a safe and feasible alternative to spare fertility of young patients without increasing risk of complication comparatively to radical hysterectomy. Postoperative complications did not impact on oncologic outcomes. To guarantee best surgical outcomes, patients eligible for RT should be referred to expert center.

\section{REFERENCES}

1. Dargent D, Martin X, Sacchetoni A, Mathevet P. Laparoscopic vaginal radical trachelectomy: a treatment to preserve the fertility of cervical carcinoma patients. Cancer 2000;88:1877-82. PUBMED | CROSSREF

2. National Cancer Institute, Surveillance, Epidemiology, and End Results Program. Cancer stat facts: cervical cancer [Internet]. Bethesda, MD: National Cancer Institute; [cited 2018 Mar 5]. Available from: https://seer.cancer.gov/statfacts/html/cervix.html.

3. Sonoda Y, Abu-Rustum NR, Gemignani ML, Chi DS, Brown CL, Poynor EA, et al. A fertility-sparing alternative to radical hysterectomy: how many patients may be eligible? Gynecol Oncol 2004;95:534-8. PUBMED | CROSSREF

4. Roy M, Plante M. Pregnancies after radical vaginal trachelectomy for early-stage cervical cancer. Am J Obstet Gynecol 1998;179:1491-6.

PUBMED | CROSSREF

5. Cibula D, Pötter R, Planchamp F, Avall-Lundqvist E, Fischerova D, Haie Meder C, et al. The European Society of Gynaecological Oncology/European Society for Radiotherapy and Oncology/European Society of Pathology guidelines for the management of patients with cervical cancer. Int J Gynecol Cancer 2018;28:641-55. PUBMED | CROSSREF

6. Bentivegna E, Maulard A, Pautier P, Chargari C, Gouy S, Morice P. Fertility results and pregnancy outcomes after conservative treatment of cervical cancer: a systematic review of the literature. Fertil Steril 2016;106:1195-1211.e5. PUBMED | CROSSREF

7. Yoon A, Choi CH, Lee YY, Kim TJ, Lee JW, Kim BG, et al. Perioperative outcomes of radical trachelectomy in early-stage cervical cancer: vaginal versus laparoscopic approaches. Int J Gynecol Cancer 2015;25:1051-7. PUBMED | CROSSREF 
8. Vieira MA, Rendón GJ, Munsell M, Echeverri L, Frumovitz M, Schmeler KM, et al. Radical trachelectomy in early-stage cervical cancer: a comparison of laparotomy and minimally invasive surgery. Gynecol Oncol 2015;138:585-9. PUBMED | CROSSREF

9. Hauerberg L, Høgdall C, Loft A, Ottosen C, Bjoern SF, Mosgaard BJ, et al. Vaginal radical trachelectomy for early stage cervical cancer. Results of the Danish National Single Center Strategy. Gynecol Oncol 2015;138:304-10. PUBMED | CROSSREF

10. Johansen G, Lönnerfors C, Falconer H, Persson J. Reproductive and oncologic outcome following robotassisted laparoscopic radical trachelectomy for early stage cervical cancer. Gynecol Oncol 2016;141:160-5. PUBMED | CROSSREF

11. Bentivegna E, Gouy S, Maulard A, Chargari C, Leary A, Morice P. Oncological outcomes after fertilitysparing surgery for cervical cancer: a systematic review. Lancet Oncol 2016;17:e240-53. PUBMED | CROSSREF

12. Lécuru F, Mathevet P, Querleu D, Leblanc E, Morice P, Daraï E, et al. Bilateral negative sentinel nodes accurately predict absence of lymph node metastasis in early cervical cancer: results of the SENTICOL study. J Clin Oncol 2011;29:1686-91. PUBMED | CROSSREF

13. Mathevet P, Lecuru F, Magaud L, Bouttitie F. Sentinel lymph node biopsy for early cervical cancer: results of a randomized prospective, multicenter study (SENTICOL 2) comparing adding pelvic lymph node dissection vs sentinel node biopsy only. Gynecol Oncol 2017;145 Suppl 1:2-3. CROSSREF

14. Marchiole P, Benchaib M, Buenerd A, Lazlo E, Dargent D, Mathevet P. Oncological safety of laparoscopicassisted vaginal radical trachelectomy (LARVT or Dargent's operation): a comparative study with laparoscopic-assisted vaginal radical hysterectomy (LARVH). Gynecol Oncol 2007;106:132-41. PUBMED | CROSSREF

15. Dindo D, Demartines N, Clavien PA. Classification of surgical complications: a new proposal with evaluation in a cohort of 6336 patients and results of a survey. Ann Surg 2004;240:205-13. PUBMED | CROSSREF

16. Beiner ME, Hauspy J, Rosen B, Murphy J, Laframboise S, Nofech-Mozes S, et al. Radical vaginal trachelectomy vs. radical hysterectomy for small early stage cervical cancer: a matched case-control study. Gynecol Oncol 2008;110:168-71. PUBMED | CROSSREF

17. Zhang D, Li J, Ge H, Ju X, Chen X, Tang J, et al. Surgical and pathological outcomes of abdominal radical trachelectomy versus hysterectomy for early-stage cervical cancer. Int J Gynecol Cancer 2014;24:1312-8. PUBMED | CROSSREF

18. Shepherd JH, Spencer C, Herod J, Ind TE. Radical vaginal trachelectomy as a fertility-sparing procedure in women with early-stage cervical cancer-cumulative pregnancy rate in a series of 123 women. BJOG 2006;113:719-24. PUBMED | CROSSREF

19. Hertel H, Köhler C, Grund D, Hillemanns P, Possover M, Michels W, et al. Radical vaginal trachelectomy (RVT) combined with laparoscopic pelvic lymphadenectomy: prospective multicenter study of 100 patients with early cervical cancer. Gynecol Oncol 2006;103:506-11. PUBMED | CROSSREF

20. Plante M, Gregoire J, Renaud MC, Roy M. The vaginal radical trachelectomy: an update of a series of 125 cases and 106 pregnancies. Gynecol Oncol 2011;121:290-7. PUBMED | CROSSREF

21. Lanowska M, Mangler M, Spek A, Grittner U, Hasenbein K, Chiantera V, et al. Radical vaginal trachelectomy (RVT) combined with laparoscopic lymphadenectomy: prospective study of 225 patients with early-stage cervical cancer. Int J Gynecol Cancer 2011;21:1458-64. PUBMED | CROSSREF

22. Li X, Li J, Wen H, Ju X, Chen X, Xia L, et al. The survival rate and surgical morbidity of abdominal radical trachelectomy versus abdominal radical hysterectomy for stage IB1 cervical cancer. Ann Surg Oncol 2016;23:2953-8. PUBMED | CROSSREF

23. Kucukmetin A, Biliatis I, Ratnavelu N, Patel A, Cameron I, Ralte A, et al. Laparoscopic radical trachelectomy is an alternative to laparotomy with improved perioperative outcomes in patients with early-stage cervical cancer. Int J Gynecol Cancer 2014;24:135-40. PUBMED | CROSSREF 
24. Pareja R, Rendón GJ, Sanz-Lomana CM, Monzón O, Ramirez PT. Surgical, oncological, and obstetrical outcomes after abdominal radical trachelectomy - a systematic literature review. Gynecol Oncol 2013;131:77-82. PUBMED | CROSSREF

25. Alexander-Sefre F, Chee N, Spencer C, Menon U, Shepherd JH. Surgical morbidity associated with radical trachelectomy and radical hysterectomy. Gynecol Oncol 2006;101:450-4.

PUBMED | CROSSREF 